\title{
Addition of vitamin D to the Irish food supply: exploring the double-edged sword
}

\author{
K.A. Emerson ${ }^{1}$, G.D. Ussher ${ }^{1}$, S.E. Kielthy ${ }^{1}$, F.E. Douglas ${ }^{1}$, O.C. Lyons ${ }^{1,2}$, D.G. O’Donovan ${ }^{3}$ \\ and M.A.T. Flynn ${ }^{1,2}$ \\ ${ }^{1}$ Public Health Nutrition, Food Safety Authority of Ireland, Dublin, Ireland, ${ }^{2}$ Northern Ireland Centre for Food and \\ Health, University of Ulster, Coleraine, BT52 1SA, UK and ${ }^{3}$ Public Analyst Laboratory, St Finbarr's Hospital, Cork, \\ Ireland
}

This abstract was awarded an oral presentation prize sponsored by Sugar Nutrition UK and the Food Safety Authority of Ireland.

Excessive, as well as inadequate, intakes of vitamin D were recently reported in Ireland ${ }^{(1)}$. Vitamin D is added to the food supply in food supplements and fortified foods. Food supplements placed on the Irish market are required to be notified to the Food Safety Authority of Ireland (FSAI) ${ }^{(2)}$. Nutrition and health claims about added vitamin D require minimal levels to be present ${ }^{(3)}$. Maximum levels for added nutrients have not yet been set. This study describes the addition of vitamin D to the Irish food supply through examination of food supplements notified since 2007 and vitamin D fortified foods marketed in Ireland.

Food supplements notified to FSAI from 2007 to 2014 ( $n 9483$ ) were assessed to identify vitamin D products. Variation in daily vitamin D dose provided (labelled values) was examined according to year notified, presentation (vitamin D-only vs. multi-nutrients) and population targeted. For a limited range of products the vitamin D content (assessed by liquid chromatography-tandem mass spectrometry) was compared with labelled values. During winter 2014 a survey established the labelled amounts of vitamin D per portion and per $100 \mathrm{~g}$ of fortified foods marketed in Ireland. For a limited number of these foods, data available on vitamin D fortification in 2007 facilitated a comparison between the two time periods.

Since 2007 there has been a significant increase in the proportion of supplements containing vitamin D notified ( $8 \%$ in 2007 vs. 20 $\%$ in $2014, \mathrm{p}<0.05)$ and in the median daily vitamin D amounts provided $(5 \mu \mathrm{g}$ in $2007 v s .7 .3 \mu \mathrm{g}$ in $2014, \mathrm{p}<0.001)$. Significantly higher median daily vitamin D amounts are presented in vitamin D-only compared with multi-nutrient preparations $(15 \mu \mathrm{g} v s .5 \mu \mathrm{g}$, $\mathrm{p}<0.001)$ and in those targeting adults/ pregnant women compared with those targeting infants/ children $(7.5 \mu \mathrm{g} v .5 \mu \mathrm{g}, \mathrm{p}<$ 0.001). Some supplements provided the tolerable level of vitamin D for populations targeted. Laboratory testing found higher dose products are less likely to be within acceptable tolerance levels for labelling ${ }^{(4)}$. In 2014, a total of 214 foods (mostly cereals, dairy foods and fat spreads) were fortified with vitamin D providing a median amount of $3 \mu \mathrm{g} / 100 \mathrm{~g}$, with some foods providing as much as $5 \mu \mathrm{g}$ per portion. For a limited number of these foods, significantly higher median amounts of vitamin D were added in 2014 compared with levels added in 2007 , as shown in the table.

\begin{tabular}{llll}
\hline & All Foods $(n 50)$ & $\begin{array}{l}\text { Cereals \& Cereal Bars }(n 39) \\
\text { Median }(\text { Range })(\mu \mathrm{g} / 100 \mathrm{~g})\end{array}$ & $\begin{array}{l}\text { Fat Spreads \& Milky Drinks }{ }^{\dagger}(n 11) \\
\text { Median }(\text { Range })(\mu \mathrm{g} / 100 \mathrm{~g})\end{array}$ \\
\hline 2007 & $1 \cdot 0(0 \cdot 0-8 \cdot 3)$ & $0 \cdot 0(0 \cdot 0-8 \cdot 3)^{*}$ & $7 \cdot 5(0 \cdot 0-8 \cdot 0)$ \\
2014 & $4 \cdot 2(0 \cdot 0-8 \cdot 3)$ & $4 \cdot 2(0 \cdot 0-8 \cdot 3)^{*}$ & $7 \cdot 5(0 \cdot 0-7 \cdot 5)$ \\
\hline
\end{tabular}

$\dagger$ milk and soya-based drinks

Median values significantly different (Wilcoxon signed-rank test): $* \mathrm{p}<0.05$

In conclusion, since 2007 significantly higher amounts of vitamin D are being added to the Irish food supply through an increase in both the number of vitamin D supplements available and in the levels of vitamin D provided in supplements and fortified food. To protect against excessive intakes of vitamin $\mathrm{D}$, safe maximum levels need to be established.

1. Kilbane et al. (2014) Ir J Med Sci 183, 485-487.

2. S.I. No. 506 of 2007 European communities (food supplements) regulations 2007 (as amended)

3. Regulation (EC) 1924/2006 on nutrition and health claims made on food.

4. European commission. Guidance on setting tolerances for nutrient values declared on a label, 2012. Available from: http://ec.europa.eu/food/food/ labellingnutrition/nutritionlabel/guidance_tolerances_december_2012.pdf 